\title{
Gastrointestinal parasites of domesticated and Feral Horses (Equus Caballus) in Sri Lanka
}

\author{
Shanika Dissanayake1, R.P.V. Jayanthe Rajapakse ${ }^{2}$ and Rupika S. Rajakaruna ${ }^{1, *}$ \\ ${ }^{1}$ Department of Zoology, University of Peradeniya, Peradeniya, Sri Lanka \\ ${ }^{2}$ Department of Veterinary Pathobiology, University of Peradeniya, Peradeniya, Sri Lanka
}

Received: 14/06/2016; Accepted: 04/02/2017

\begin{abstract}
Horses are not native to Sri Lanka. They are imported from neighbouring countries to be used for police work, sporting or riding and esthetic purposes. An isolated population of about 500 feral horses lives in the Delft Island in northern Sri Lanka. These feral horses served hundred years for western conquests and when they left Sri Lanka, horses were left behind in the Delft Island. There are no records of gastrointestinal (GI) parasites of horses in Sri Lanka and the present study was carried out to determine the GI parasites in the domesticated (free grazing and stabled) and feral horses. Fresh faecal samples were collected from horses and analysed qualitatively and quantitatively to determine the types of GI parasites and their prevalence and intensity. Qualitative analyses using direct saline and iodine mounts, simple test tube flotation, Sheather's modified sucrose flotation and sedimentation technique were carried out followed by McMaster counting technique for the positive samples. Identification of parasites involved morphological, morphometric and molecular methods. A total of 73 horses were sampled. All the feral horses $(n=14)$ were infected. Among the domesticated horses, free grazers had a significantly higher prevalence of GI infections $(46.7 \%)$ than the stabled ones $\left(18.2 \%\right.$; Chi square test $\chi^{2}=4.787$, df $=1, p=$ $0.029)$. There was no significant difference between helminth and protozoan infections among the three groups of horses (Chi square test, $\chi^{2}=1.453, \mathrm{df}=2, p$ = 0.484). Six species of parasites: Anoplocephala sp., Parascaris equorum, Strongylus sp. Isospora sp. Entamoeba sp. and Giardia sp. were recorded. Strongylus infections were recorded in all the feral horses with a high intensity but not in any of the domesticated animals. Strongylus is a highly pathogenic and the most damaging parasite of horses worldwide. It is important to investigate whether Strongylus infection is responsible for the high mortality recorded in the feral horses in the Delft Island especially because the Department of Wildlife Conservation is to declare Delft Island a National Park to conserve the feral horses.
\end{abstract}

Keywords: Horses, Gastrointestinal parasites.

\section{INTRODUCTION}

Horses, Equus caballus (Linnaeus, 1758) are not native to Sri Lanka. Tamed horses are continuously being imported to Sri Lanka from few neighboring countries and are used for police work, sporting or riding and esthetic purposes. Geld males are more frequently imported than mares because of suitability of male horses for working purpose. Although geld horses are calmer and gentler and serve the purpose, the country has to depend on constant supply of horses due to their low reproductive success. About 150 domesticated horses are sporadically distributed in the country (Personal communication, Veterinary Teaching Hospital Peradeniya). Most of these horses are thoroughbred with few cold blood and warm blood breeds. In major cities like Colombo, Kandy and Nuwara Eliya, the horses are used in police work. Race horses of private owners are also found in these areas. In addition, few horses are used for riding in parks, hotels and recreational areas as an income source for the owner. All the domesticated horses in Sri Lanka receive veterinary care some with regular worm treatment and vaccination. Horses perform their work as long as they can (approximately for 20 years) and when horses grow old or injured and unable to perform their duties they are sold to household private owners for low prices (Personal communication).

In addition to these domesticated horses, an isolated population of about 500 feral horses is in the Delft Island in northern Sri Lanka. The island covers approximately 4,700 ha and is sparsely populated, unscathed due to the 30 year civil war which ended recently. Horses had been introduced by the Portuguese rulers of the island in the 1600s. Then they went to the hands of Dutch after the war in 1658. When British 
conquered the area under Dutch in 1796 these horses became a property of them and started to breed them and used them for transport (http://unep.ch/islands/). Today, most of them roam freely, although some are owned by civilians in the island and the Sri Lanka Navy, they are all left to free-graze. There is no veterinary care of any sort but the horses are adapted to low food and water and extreme climate conditions in the island. Now the island is a major tourist attraction, mainly due to these feral horses. A protection law has been placed over the feral horses and it is forbidden to remove them from the island which is soon to be declared a sanctuary (Personal communication, Department of Wildlife Conservation, Sri Lanka).

Horses are known as hosts for variety of internal and external parasites (Steelman, 1976; Rubenstein and Hohmann, 1989; Rehbein et al., 2013). Ticks, lice, mites, flies and mosquitoes are common external parasites on horses while blood and gastrointestinal (GI) parasites are considered as common internal parasites. Horses are susceptible to more than 60 GI parasites and may harbor several species of worms at any time (Anazi et al., 2011). These parasites have the potential to cause serious disease including diarrhea, emaciation, colic, anaemia, haemorrhage and even death (Anazi et al., 2011). Factors like age, sex, breed, physiological status of the host affect the intensity and prevalence of infection of GI parasites in horses (Brucknell et al., 1995; Lind et al., 1999; Larsen et al., 2002; Francisco et al., 2009; Lyons et al., 2012) which can be more serious in young and undernourished horses and mares (Lyons et al., 2012).

Among nematodes, strongyle and Parascaris equorum (horse ascarid) infections are the most commonly diagnosed infections in horses (Epe et al., 2004; Hinney et al., 2011, Reihbein et al., 2012). Family Strongylidae is the largest group of GI parasites infecting horses worldwide, consisting over 50 known species in two subfamilies: large strongyle (Subfamily: Strongylinae) and small strongyle (Subfamily: Cyathostominae) (Flangn et al, 2013). Among them, three species of strogyles: Strongylus vulagaris, $S$. edentates and $S$. equinus are known to be more pathogenic parasites of horses. Moreover, severe infections with horse ascarid, $P$. equorum also can result clinically drastic consequences such as obstruction and/or penetration of the small intestine, the latter usually leads to death. Other than strongyle and ascarid infections, pinworm (Oxyris equi), lungworms (Dictyocaulus arnfieldi), Habronema and Draschia are frequently recorded nematodes in horse GI tract (Brucknell et al., 1995; Francisco et al., 2009; Anazi et al., 2011).

Cestodes and trematodes are also recorded inhorses. Anoplocephala is the most common cestode in horses worldwide (Soulsby, 1982; Taylor et al., 2007; Andresen et al., 2012; Gatachew et al., 2012). Three species of Anoplocephala have been recorded in horses: Anoplocephala perfoliata, A. magna, A. mamillana (formerly Paranoplocephala mamillna) (Soulsby, 1982; Taylor et al., 2007). Earlier, it was reported that A. magna and A. mamillana as the most common tapeworm while A. perfoliata as a rare species in horses (Olsen, 1938). However, recent studies report that $A$. perfoliata as the dominant equine tapeworm worldwide (Gasser et al., 2005). Among the trematodes, Fasciola hepatica and Dicrocoelium dentriticum are recorded in horses with relatively low infections (Brucknell et al., 1995). Horse bots also common GI infections in horses, but vector of horse bot fly is not found in Sri Lanka.

Among the protozoans, the cysts of Eimeria spp. (E. solipedum and E. leuckarti), Cryptosporidium sp. and Giardia sp. have been recorded in horses (Gawor, 1995; Papazahariadou et al., 2009). These parasites have the potential to cause serious illness including diarrhea, emaciation, colic, anaemia, haemorrhage and even death (Anazi et al., 2011). In addition, they can lead to reduced performance and condition due to poor growth and weight loss. They are more common in free grazing equines and present a greater threat to their health and welfare than those kept and fed in stables.

Gastrointestinal parasites of horses in Sri Lanka have not been studied previously. Here we present the results of an island-wide, cross sectional coprological survey of GI parasites in feral and domesticated horses in Sri Lanka.

\section{MATERIALS AND METHODS}

\section{Study animals}

Horses and ponies are considered as one species, E. caballus. The only difference is, ponies are 
smaller in size than horses (horses below height of 14.2 hands are known as ponies), hence the term "horse" is frequently used to refer both ponies and horses (Boulton, 2013). In the present study, samples from both ponies and horses were collected and from here onwards the term "horse" will be used to refer to both.

Both domesticated (Equus caballus caballus) and feral horses (Equus caballus ferus) were sampled. Domesticated horses in Sri Lanka are distributed as isolated herds and under different management practices. Stabled horses are those used for police work and as race horses. They are fed inside the stable all the time and are not allowed to free graze. All these stabled horses receive regular veterinary care (deworming, vaccination), grooming, bathing and treatment for ectoparasites. All the racecourses and police have stabled horses.
Privately owned horses are mostly free grazers, and are used in recreational purposes in parks. Although the owners claimed that they receive veterinary care, there were no records and the treatments were not regular. Feral horses are free grazers confined to Delft Island which is located $10 \mathrm{~km}$ away from the mainland close to Jaffna Peninsular (Figure 1). These feral horses do not receive any veterinary care or treatment, grooming or treatment for ectoparasites.

\section{Study sites}

Samples were collected from two types of domesticated horses: stabled horses in Nuwara Eliya racecourse, Kandy and Colombo Police station and privately owned, free grazing horses in Nuwara Eliya, Peradeniya and Anuradhapura. All the feral horses were sampled from the Delft Island (Figure1).

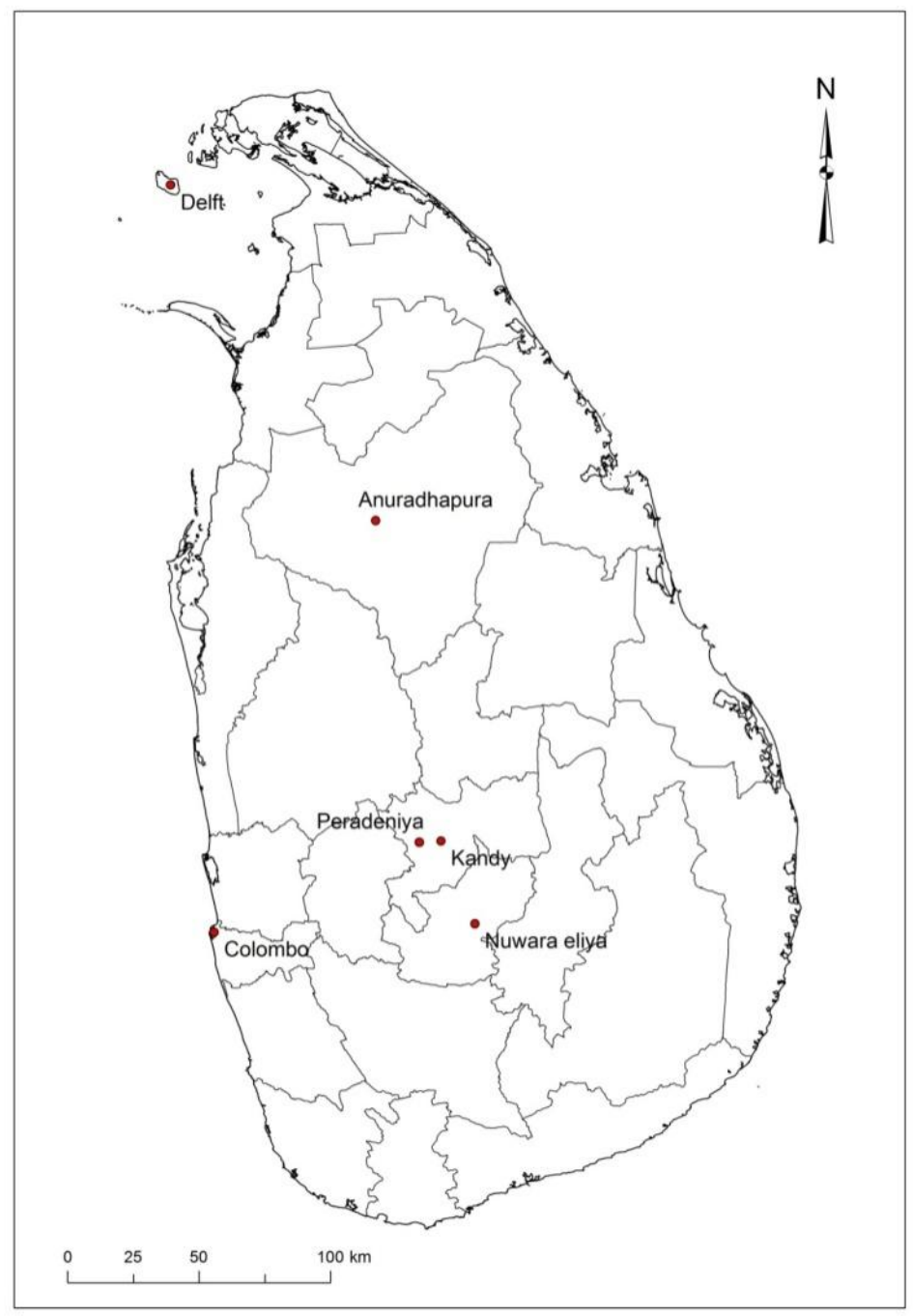

Figure 1: Map showing the sample collection sites in Sri Lanka. 
Colombo, Kandy, Nuwara Eliya and Peradeniya are in the Wet zone of Sri Lanka. Nuwara Eliya is situated at $6.97^{\circ}$ North latitude, $80.78^{\circ}$ East longitude and $2085 \mathrm{~m}$ above the sea level having low temperatures throughout the year with a mean of $16{ }^{\circ} \mathrm{C}$ a mean precipitation of $2300 \mathrm{~mm}$. Kandy is situated at $7.3^{\circ}$ North latitude, $80.64^{\circ}$ East longitude and $473 \mathrm{~m}$ above the sea level with $22^{\circ} \mathrm{C}$ mean annual temperature and rainfall of $1840 \mathrm{~mm}$. Nuwara Eliya and Kandy are in the Central Province of Sri Lanka. Colombo, the commercial capital is situated at $6.93^{\circ}$ North latitude, $79.85^{\circ}$ East longitude in the Western Province of Sri Lanka with $1 \mathrm{~m}$ elevation above the sea level. It has a mean annual temperature of $28{ }^{\circ} \mathrm{C}$ and annual rainfall of $2500 \mathrm{~mm}$.

Anuradhapura and Delft Island is located in the Dry zone of Sri Lanka. Anuradhapura in the North Central Province of Sri Lanka at an average elevation of $100 \mathrm{~m}$, receives an annual rainfall of $1500 \mathrm{~mm}$ and has an annual temperature of $29{ }^{\circ} \mathrm{C}$. The environment in the Delft Island is harsh because of high temperature, low rainfall and high dry wind. Food and water for the horses are scarce. Horses live in Delft somehow manage to survive with low food and water and in extreme climate conditions. Delft is an Island surrounded by the Indian Ocean (length of the island is $8 \mathrm{~km}$; width about $6 \mathrm{~km}$; area $50 \mathrm{~km}^{2}$ ) near Jaffna peninsula and belongs to Northern Province. It is situated at $9^{\circ} 31^{\prime}$ North latitude, $79^{\circ} 40^{\prime}$ East longitude and $7 \mathrm{~m}$ above the sea level. Throughout the year, high winds and high temperature persist with an average of $28{ }^{\circ} \mathrm{C}$ and a very low $(600 \mathrm{~mm})$ annual rainfall. Thorny shrubs and dry pastures are the main vegetation type which are less productive and sporadically distributed. Since water and food are scarce, the environment conditions are harsh for dwelling animals.

\section{Collection and analysis of faecal samples}

Fresh faecal samples were collected from January to August 2014 from domesticated and feral horses soon after defecating. Parasite eggs and cysts were isolated using direct saline and iodine mounts, simple test tube flotation, Sheather's modified sucrose flotation method and sedimentation technique. For the positive samples, a quantitative analysis using the McMaster counting technique was carried out. A special staining procedure was carried out to identify Giardia cysts (Trichrome stain).
Morphological and morphometric identifications were confirmed by molecular methods. Morphological identification was done according to the photo guides and text books (Soulsby et al., 1968; http://www.cdc.gov; http://www. merckmanuals.com/vet/). Number of eggs, oocysts and cysts in $0.5 \mathrm{~mL}$ was estimated in gram of faeces as EPG/CPG or OPG. Cysts and oocyst isolation was done by the Sheather's sucrose floatation method. Length and the width of eggs and cysts were measured under high power $(10 \times 40)$ for morphometric identification. Prevalence of GI parasites in domesticated (free grazing and stabled) and feral horses was compared using a Chi square test.

\section{Modified salt floatation method}

Approximately $3 \mathrm{~g}$ of faeces was measured and was taken into a $50 \mathrm{~mL}$ capped centrifuge tube. The volume was made up to $50 \mathrm{~mL}$ by adding distilled water, and it was mixed thoroughly using a wooden applicator. This suspension was centrifuged at $2045 \mathrm{~g}$ for $20 \mathrm{~min}$. The supernatant was discarded and the pellet was washed twice by re-suspending in distilled water followed by two centrifugations until a clear supernatant was obtained. The pellet was then emulsified with saturated salt and was mixed thoroughly. It was centrifuged again for $20 \mathrm{~min}$ at 2045 g. Approximately $5 \mathrm{~mL}$ of the top meniscus was aspirated and added to a $15 \mathrm{~mL}$ centrifuge tube. The total volume was made up to $15 \mathrm{~mL}$ by adding distilled water and centrifuged for $10 \mathrm{~min}$ at $1370 \mathrm{~g}$. This was repeated and finally $1 \mathrm{~mL}$ of the suspension with the pellet was mixed and transferred to a $1.5 \mathrm{~mL}$ Eppendorf® microfuge tube using a pasteur pipette. Distilled water was added to make it up to $1.5 \mathrm{~mL}$ and centrifuged for $10 \mathrm{~min}$ at $1150 \mathrm{~g}$ in the microcentrifuge. The supernatant was decanted and the pellet was mixed thoroughly with $0.5 \mathrm{~mL}$ of the supernatant. Microscope slides were prepared using about $0.1 \mathrm{~mL}$ of the suspension and covered with a cover slip without staining. Five smears were observed from each sample under the light microscope. Eggs of different species were identified and the number of eggs and cysts in $0.5 \mathrm{~mL}$ was estimated and eggs per gram (EPG) of faeces were calculated assuming the method had concentrated all the eggs in the $3 \mathrm{~g}$ of faeces into $0.5 \mathrm{~mL}$. 


\section{Sheather's sucrose floatation method}

Oocyst isolation was done using Sheather's saturated sucrose as the floatation fluid instead of salt, following the same method described under the modified salt flotation method. Number of cysts and eggs of a particular species in each sample was calculated as an EPG value as mentioned above.

\section{Direct saline and iodine smears}

A drop of saline and a drop of iodine solution were placed separately on a glass microscope slide. A small portion (size of a match head) of the faecal sample was picked up using a toothpick and was mixed with the drop of saline. This was repeated with the drop of iodine. The two smears were covered with separate cover slips and observed under the light microscope. Eggs and cysts were identified and their relative numbers in a sample size of a match head was estimated. The length and the width of eggs and cysts isolated were measured using the calibrated eye piece graticule under high power $(10 \times 40)$.

\section{Identification of larvae}

Helminth eggs were cultured and larvae were obtained according to the method described in Rajapakse et al., 1992. Freshly harvested nematode eggs were placed in Petri dishes in 0.1 $\mathrm{N}$ sulphuric acid at a depth of $0.5 \mathrm{~cm}$ in room temperature $\left(22-24{ }^{\circ} \mathrm{C}\right)$ to incubate. Embryonated eggs containing infective larvae were washed three times in distilled water by centrifugation at $1150 \mathrm{~g}$ for $10 \mathrm{~min}$ to remove sulphuric acid and other organic matter. One milliliter quantities of the suspension were transferred to five $50 \mathrm{~mL}$ plastic centrifuge tubes. To each tube, $10 \mathrm{~mL}$ of saturated calcium hypochlorite solution at room temperature was added. Every five minutes, one tube with suspension was diluted to $50 \mathrm{~mL}$ with distilled water, in order to prevent any further de-coating action on the egg shell by the calcium hypochlorite solution. Eggs at the bottom of the tube were observed under the microscope to select the tube with eggs at the suitable decoating stage with larvae coming out of eggs. Then the selected tubes were centrifuged at 1150 $\mathrm{g}$ for $10 \mathrm{~min}$. After removal of the supernatant, suspensions were washed ten times (1150 g for $10 \mathrm{~min}$ ) and the hatched larvae at the bottom of the test tube were collected.

\section{Molecular identification}

Molecular methods were used to confirm the morphological and morphometric identification of nematodes using internal transcribed spacer (ITS)-2(5'GCTGCGTTCTTCATCGATGC'3, White et al., 1990) primer. Presence of $P$. equorum and Strongylus were confirmed using species specific primers. Eggs were concentrated into a small portion of water by centrifuging with floatation solution followed by water. About 2030 eggs from each parasite were picked up using pasture pipette into a separate Eppendorf® tube. Gene extraction was done using Dongsheng Biotech DNA extraction kit. Amplification of DNA was done using PCR (Polymerase Chain Reaction; final volume $25 \mu \mathrm{l}$ ) with $10 \mathrm{ng}$ genomic extraction using the ITS-2 primer. PCR conditions used were $5 \mathrm{~min}$ denaturation at $94^{\circ} \mathrm{C}$; 40 cycles at $94^{\circ} \mathrm{C}$ for $1 \mathrm{~min}$, at $50^{\circ} \mathrm{C}$ for $1 \mathrm{~min}$ and at $72^{\circ} \mathrm{C}$ for $1 \mathrm{~min}$ annealing; followed by final $7 \mathrm{~min}$ extension at $72^{\circ} \mathrm{C}$. PCR products were subjected to gel electrophoresis.

\section{RESULTS}

\section{Prevalence of GI parasites}

A total of 73 faecal samples were collected including 44 samples from the domesticated stabled, 15 domesticated free grazing and 14 feral horses. All the feral horses were infected with both protozoan and helminth GI parasites (Table 1). Among the domesticated horses free grazing horses had a significantly higher prevalence of GI infections (46.7\%) than those of the stabled ones $\left(18.2 \%\right.$; Chi square test $\chi^{2}=$ 4.787, $\mathrm{df}=1, p=0.029)$. Free grazing domesticated horses had a higher percentage of helminthes (13.3\%) and protozoans (46.7\%) than the stabled horses (Hlminthes $=9.1 \%$ and protozoans $20.4 \%$ ). However, there was no significant difference between helminth and protozoan infections among the three groups of horses (Chi square test, $\chi^{2}=1.453, \mathrm{df}=2, p=$ 0.484). Among those Mounted Police horses, in Colombo horses were dewormed few months before sampling but they harboured both helminthes (16.5\%) and protozoans (27.8\%) while those from Kandy only one horse was infected with protozoans (12.5\%; Table 1). 
Table 1: Prevalence of gastrointestinal parasite of horses sampled at different sites under different management systems.

\begin{tabular}{|c|c|c|c|c|c|c|}
\hline \multirow[t]{2}{*}{ Management } & \multirow[t]{2}{*}{ Sampling site (n) } & \multirow{2}{*}{$\begin{array}{l}\text { Sampling } \\
\text { Date }\end{array}$} & \multirow{2}{*}{$\begin{array}{c}\text { Last } \\
\text { Deworming } \\
\text { Date }\end{array}$} & \multicolumn{3}{|c|}{ Prevalence \% } \\
\hline & & & & overall & Helminths & Protozoa \\
\hline \multirow{5}{*}{$\begin{array}{l}\text { Domesticated \& free } \\
\text { grazing }\end{array}$} & Nuwara Eliya race course (8) & 06.05 .2014 & Unknown & 30.0 & 0.0 & 30.0 \\
\hline & Public Park Kandy (1) & 07.08 .2014 & Unknown & 0.0 & 0.0 & 0.0 \\
\hline & Peradeniya University premises (3) & 12.07.2014 & Unknown & 66.7 & 66.7 & 66.7 \\
\hline & Kundasale privately owned (2) & July 2014 & Unknown & 50.0 & 0.0 & 50.0 \\
\hline & Anuradhapura privately owned (1) & 04.10 .2014 & January 2014 & 100.0 & 100.0 & 0.0 \\
\hline Total & (15) & & & 46.7 & 13.3 & 46.7 \\
\hline \multirow{3}{*}{$\begin{array}{l}\text { Domesticated \& } \\
\text { stabled }\end{array}$} & Nuwara Eliya race course (18) & 14.01 .2014 & 03.11 .2013 & 27.8 & 11.1 & 16.7 \\
\hline & Kandy Mounted Police (8) & 20.02.2014 & 18.10 .2013 & 12.5 & 0.0 & 12.5 \\
\hline & Colombo Mounted Police (18) & 15.08 .2014 & February 2014 & 33.3 & 16.7 & 27.8 \\
\hline Total & (44) & & & 25.0 & 9.1 & 20.4 \\
\hline Feral horse & Delft Island (14) & 29.08 .2014 & No de-worming & 100.0 & 100.0 & 100.0 \\
\hline Grand total & (73) & & & 433.8 & 27.4 & 41.1 \\
\hline
\end{tabular}

$\mathrm{n}=$ number of horses sampled 
Table 2: Type of gastrointestinal parasite, its prevalence and intensity of infection in feral and domesticated equines.

\begin{tabular}{|c|c|c|c|c|c|c|c|c|}
\hline \multirow{3}{*}{ Parasitic group } & \multirow{3}{*}{ Parasite } & \multirow[b]{3}{*}{ Overall } & \multirow{2}{*}{\multicolumn{2}{|c|}{$\begin{array}{l}\text { Prevalence \% } \\
\text { Domestic }\end{array}$}} & \multirow[b]{3}{*}{ Feral } & \multicolumn{3}{|c|}{ EPG/OPG/CPG Range } \\
\hline & & & & & & \multicolumn{2}{|c|}{ Domestic } & \multirow{2}{*}{ Feral } \\
\hline & & & $\begin{array}{c}\text { Free } \\
\text { grazing }\end{array}$ & Stabled & & $\begin{array}{c}\text { Free } \\
\text { grazing }\end{array}$ & Stabled & \\
\hline \multirow[t]{3}{*}{ Protozoans } & Isospora $\mathrm{sp}$. & 13.7 & 0.0 & 13.6 & 28.6 & 0 & $50-200$ & $200-300$ \\
\hline & Entamoeba sp. & 28.8 & 20.0 & 18.2 & 71.4 & $50-200$ & $50-200$ & $200-300$ \\
\hline & Giardia sp. & 4.1 & 0.0 & 0.0 & 21.4 & 0 & 0 & $100-200$ \\
\hline Cestodes & Anoplocephala sp. & 2.7 & 0.0 & 2.3 & 7.1 & 0 & 50 & 50 \\
\hline \multirow[t]{2}{*}{ Nematodes } & Parascaris equorum & 16.4 & 20.0 & 6.8 & 42.8 & $100-200$ & $100-200$ & $200-400$ \\
\hline & Strongylus sp. & 19.2 & 0.0 & 0.0 & 100.0 & 0 & 0 & $500-1600$ \\
\hline
\end{tabular}




\section{Types and intensity of GI parasites}

A total of six types of parasites: three helminth species (Anoplocephala sp., Parascaris equorum and Strongylus sp.) and three protozoan parasites (Entamoeba sp., Giardia sp. and Isospora sp.) were recorded in feral horses of which Strongylus sp. and Giardia sp. were absent in domesticated horses (Table 2; Figure 2). Strongylus were the most common helminth recorded at high intensity (mean EPG 814.3) in all the feral horses but not in any of the domesticated animals. The second most common infection was the equine round worm, Parascaris equorum (Ascarid; 16.7\%), which were recorded in both domestic and feral horses. A significantly higher number of feral horses $(42.8 \%)$ were infected with $P$. equorum compared to the domesticated $(10.2 \%)$ horses (Chi square test; $p$ $<0.05$ ). Intensity of infections was higher in feral horses than domesticated ones. High intensity of Strongylus (500-1600 EPG) was observed.

The equine tapeworm, Anoplocephala infections were recorded in both domesticated and feral horses at low intensities (50 EPG). All the feral horses were infected with Entamoeba (Table 2). Of all the infections, domesticated horses didn't have two important GI parasites: Giardia and Strongylus sp. Mixed infections were not recorded in domesticated horses whereas all the feral horses had mixed infections of helminth and protozoans. Furthermore, 50\% of feral horses had mixed helminth infections, of which Strongylus and P. equorum was the most common infection (42.8\%) followed by Strongylus and Anoplocephala infection (7.1\%).

\section{DISCUSSION}

All the feral horses were infected with GI helminthes and protozoans. Of the domesticated horses, the prevalence of GI infections was higher among the free grazers than the stabled horses. None of the feral horses were dewormed or received any veterinary care where as all the domesticated horses were treated for GI infections. However, due to free grazing behaviour of some of the domesticated animals, a higher prevalence of infections was recorded compared to the stabled horses. The grazing animals are always exposed to parasites regularly than those fed inside stables and are thus constantly being reinfected even they were dewormed regularly. Therefore, it is a challenging task to control GI parasites in free grazing horses even by administering different types of treatments and multi directional approaches.

Although all the horses in mounted police were given regular deworming and were under similar management conditions, a higher prevalence of GI parasites (33.3\%) was recorded among the horses in the mounted police in Colombo than those in Kandy (12.5\%). This could be because the deworming practices were different in the two stations. In Colombo, horses were treated one at a time for GI parasites while in Kandy all the animals in the station were treated simultaneously. Moreover, sampling of horses in Colombo was done six months after the last deworming date but in Kandy sampling was carried out in four months after deworming.

Feral horses in Delft Island were infected with six types of GI parasites and of which Gairdia and Strongylus infections can be considered important. Both these parasites were absent in the domesticated horses. All the feral horses were infected with Strongylus with high worm burden (500-1600 EPG). Strongylus is the most common and most damaging parasite of horses worldwide (Reinemeyer et al., 1984; Bucknell et al., 1995; Pilo et al., 2012; Flanagan et al., 2013). It is a highly pathogenic parasite. Absence of Strongylus infections in domesticated horses could be due to effectiveness of antihelminthics given to them.

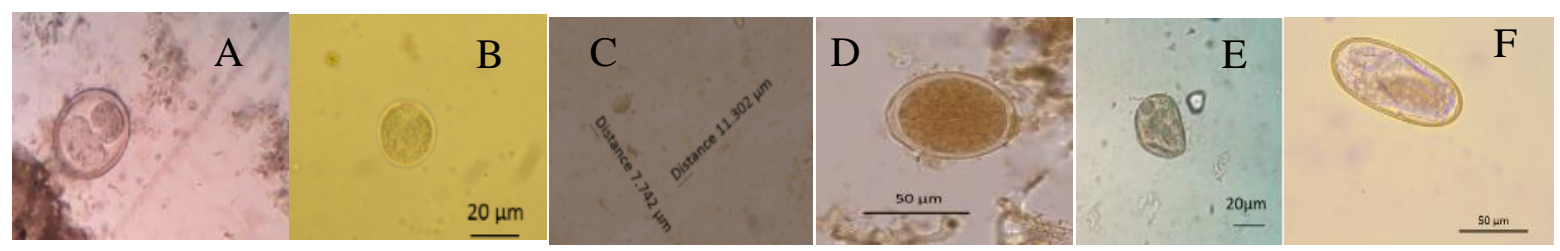

Figure 2: Eggs and cysts of gatro-intestinal parasites identified in the feacal samples of feral and domesticated equines A) Isospora cyst, B) Entamoeba cyst, C) Giardia cyst, D) Parascaris equorum egg, E) Anoplocephala egg, F) Strongylus egg. 
Among the Strongylus species S. vulgaris is the most prevalent and most pathogenic species that infect horses (Lyons et al., 2012; Pilo et al., 2012; Rehbein et al., 2012). Adult worms live in the caecum and right ventral colon. Fourth and fifth stage larvae are responsible for arthritis, necrosis, and fibrosis of infected horses. Alterations in blood parameters and blood chemistry have been observed in horses infected with S. vulgaris (Pilo et al., 2012; Flanagan et al., 2013). Horses can die from a severe infection. Many deaths of feral horses have been reported from the Delft Island and a possible contribution of Strongylus sp. in high intensity cannot be ruled out in this regard.

Low prevalence of the cestode, Anoplocephala was found in both feral and domesticated horses. Adult stages of three species of Anoplocephala infect equines: $A$. magma, A. perfoliata and A. mamillana, of which $A$. perfoliata is the most dominant intestinal tapeworm of horses worldwide (Bucknell et al., 1995; Rehbein et al., 2012; Flanagan et al., 2013) and is responsible for equine colic, risk of ileal impaction and other intestinal disorders in horses (Reinemeyer et al., 1984; Getachew et al., 2012).

Both feral and domesticated horses had $P$. equorum infection which is an equine specific roundworm that can infect horses, donkeys and zebras but not humans and other animals. It has a cosmopolitan distribution and is considered the most difficult equine parasite to treat as it requires larger doses of powerful anthelmintic drugs than for other equine parasites. A significantly higher number of feral horses (43\%) were infected with $P$. equorum compared to the domesticated (10\%) horses. Parascaris equorum had known to evolve antihelmintic resistance (Himmelstierna, 2012) and this could be the reason for the presence of the parasite in domestic horses in Sri Lanka even after anthelmintic treatments. Both $P$. equorum and Anoplocephala may also potentially cause severe damages to horses depending on their intensities (Rehbein et al., 2012). Faecal analyses are becoming increasingly important for equine establishments as a means of parasite surveillance and detection of anthelmintic resistance. For example, the prevalence of large strongyles has increased in horses since the $1980 \mathrm{~s}$ in areas where broad spectrum anthelmintics have been frequently used (Pilo et al., 2012). Reduced use of these broad scale chemicals helps to prolong their efficacy against parasites and it also lower the cost to maintaining equines (Himmelstierna, 2012; Flanagan et al., 2013)

Except for Giardia infection which was absent in domesticated horses, other two protozoans were present at moderate infection of other protozoans recorded in the study do not cause severe damage to the horses. Feral horses recorded a significantly higher percentage prevalence $(71 \%)$ of Entamoeba than the domesticated horses (19\%). Among the parasites recorded Isospora, Entamoeba and Giardia, are zoonotic infections and are known to cause diarrhea, abdominal pain, anoxia, and vomiting in humans.

Delft Island is soon to be declared a National Park by the Department of Wildlife Conservation, Sri Lanka mainly because of the presence of these feral horses. Recently, many deaths of the feral horses in Delft Island have been reported and the possible contribution of GI parasites to their mortality cannot be ruled out. However, postmortem examinations need to be carried out in order to confirm this.

\section{REFERENCES}

Anazi, A.D. and Alyousif, M.S. (2011) Prevalence of non-strongyle gastrointestinal parasites of horses in Riyadh region of Saudi Arabia. Saudi Journal of Biological Science 18: 299-303.

Andersen, U.V., Howe, D.K., Olsen S.N. and Nielson M.K. (2012). Recent advances in diagnosing pathogenic equine gastrointestinal helminthes: The challenge of prepatent detection. Veterinary Parasitology. 192: 1-9.

Boulton, T. (2013) Difference between a pony and a horse. [Online] 21st June 2013. Available from: http://www.todayifoundout.com/index.php/2013/ 06/the-difference-between-a-pony-and-a-horse/ [Accessed 8th August 2015].

Bucknell, D.G., Gasser, R.B. and Beveridge, I. (1995) The prevalence and epidemiology of gastrointestinal parasites of horses in Victoria, Australia. International Journal of Parasitology 25: 711-724.

Epe, C., Coati, N. and Schnieder, T. (2004) Results of parasitological examinations of faecal samples from horses, ruminants, pigs, dogs, cats, hedgehogs and rabbits between 1998 and 2002. Europe PMC 111:243-247.

Flanagan, K.L., Morton, J.M. and Sandeman, R.M. (2013) Prevalence of infection with gastrointestinal nematodes in Pony Club horses in 
Victoria. Australian Veterinary Journal 91: 241245.

Francisco, I., Arias, M., Cortiñas, F.J., Francisco, R., Mochales, V., Dacal, V., Suárez, J.L., Uriarte, J., Morrondo, P., Sánchez-Andrade, R., Díez-Baños, P. and Paz-Silva, A. (2009). Intrinsic factors influencing the infection by helminth parasites in horses under an Oceanic Climate Area (NW Spain). Journal of Parasitology Research. 7: 225-230.

Gasser, R.B., Williamson, R.M.C. and Beveridge, I. (2005) Anoplocephala perfoliata of Horsessignificant scope for further research, improved diagnosis and control. Parasitology 131: 1-13.

Gawor, J.J. (1995) The prevalence and abundance of internal parasites in working horses autopsied in Poland. Veterinary Parasitology 58: 99-108.

Getachew, A.M., Innocent, G., Proudman, C.J., Trawford, A., Feseha, G., Reid, W.J., Faith, B. and Love, S. (2012) Equine cestodosis: a seroepidemiological study of Anoplocephala perfoliata infection in Ethiopia. Veterinary Research Communications 36: 93-98.

Himmelstierna, G.V.S. (2012) Anthelmintic resistance in equine parasites - detection, potential clinical relevance and implications for control. Veterinary Parasitology 185, 2-8.

Hinny, B., Wirtherle, N.C., Kyule, M., Miethe, N., Zessin, K.H. and Clausen, P.H. (2011). Prevalence of Helminths in horses in the state of Braden-burg, Germany. Parasitology Research.108: 1083-1091.

Johnson, E., Alwill, E.R., Filkins, M.E. and Kalush, J. (1997) The prevalence of Shedding of Cryptosporidium and Giardia spp. Based on Single Fecal Collection from Each of 91 Horses Used for recreation. Journal of Veterinary Diagnostic Investigation 9: 56-60.

Larsen, M.M., Lendal, S., Chriél, M., Olsen, S.N. and Bjørn, H. (2002). Risk factors for high endoparasitic burden and the efficiency of a single anthelmintic treatment of Danish horses. Acta Veterinaria Scandinavica. 43: 99-106.

Lind, E.O., Höglund, J., Ljungström, B.L., Nilsson, O. and Uggla, A. (1999). A field survey on the distribution of strongyle infections of horses in Sweden and factors affecting faecal egg counts. Equine Veterinary Journal. 31: 68-72.

Linnaeus, C. (1758) Systemanaturae, per regna trianaturae, secundum classes ordines, genera, species cum characteribus differentiis, synonymis, locus, $10^{\text {th }}$ Ed. Salvii Holmiae Pp. 73.

Lyons, E.T., Tolliver, S.C. and Kuzmina, T.A. (2012) Investigation of strongyle EPG values in horse mares relative to known age, number positive, and level of egg shedding in field studies on 26 farms in Central Kentucky (2010-2011). Parasitology Research 110: 2237-2245.

Olsen, O.W. (1983) Anoplocephalosis in Minnesota horses. Journal of American Veterinary Medical Association 92: 557-559.

Papazahariadou, M., Papadopoulos, E., Diakou, A. and Ptochos, S. (2009). Gastrointestinal parasites of stabled and grazing horses in Central and Northern Greece. Journal of Equine Veterinary Science 29:233-236.

Pilo, C., Alteaa, A., Pirinob, S., Nicolussic, P., Varcasiaa, A., Genchid, M. and Scalaa, A. (2012) Strongylus vulgaris (Looss, 1900) in horses in Italy: Is it still a problem? Veterinary Parasitology 184: 161-167.

Rajapakse, R.P.V.J., Vasanthathilake, V.W.S.M., Lloyd, S. and Fernando, S.T. (1992) Collection of eggs and hatching and culturing second-stage larvae of Toxocara vitulorum in vitro. Journal of Parasitology 78:1090 - 1092.

Rehbein, S., Visser, M. and Winter, R. (2012) Prevalence, intensity and seasonality of gastrointestinal parasites in abattoir horses in Germany. Parasitology Research 112:407-413.

Reinemeyer, C.R. and Nielsen, M.K. (2013) Biology and Life Cycles of Equine Parasites. In: Handbook of Equine Parasite Control, $1^{\text {st }}$ Ed., John Wiley \& Sons, Inc. pp 3-22.

Reinemeyer, C.R., Smith, S.A., Gabel, A.A, and Herd, R.P. (1984). The prevalence and intensity of internal parasites of horses in the USA. Veterinary Parasitology 15: 75-83.

Rubenstein, D. I. and Hohmann, M. E. (1989). Parasites and social behavior of island feral horses. Oikos 55: 312-320.

Soulsby, E.J.L. (1968). Helminths, arthropods and protozoa of domesticated animals. London: BaillièreTindall and Cassell Ltd.

Steelman, C.D. (1976). Effects of External and Internal Arthropod Parasites on Domestic Livestock Production. Annual Review of Entomology. 21:155-178.

Taylor, M.A., Coop, R.L. and Wall, R.L. (2007). Veterinary Parasitology. Oxford, UK; Iowa, USA; Victoria, Australia. Blackwell Publishing.

White, T.J., Bruns T., Lee S. and Taylor, J. (1990). Amplification and direct sequencing of fungal ribosomal RNA genes for phylogenetics. In: Innis M.A., Gelfand D.H., Sninsky J.J. and White T.J. (Eds) PCR Protocols: a guide to methods and applications. USA: Academic Press, New York Pp. 315-322.

Wilson, D.E., and Reeder, D.M. (1993) Mammal species of the world, a taxonomic and geographic reference..Smithsonian Institute Press, Washington, District Columbia pp 1206. 